\title{
Optimizing frontline therapy in advanced urothelial cancer
}

\author{
Whi-An Kwon ${ }^{1}$, Ho Kyung Seo ${ }^{2}$ \\ ${ }^{1}$ Department of Urology, Myongji Hospital, Hanyang University College of Medicine, Goyang, Gyeonggi-do, Republic of Korea; ${ }^{2}$ Department of \\ Urology, Center for Urologic Cancer, Hospital/Division of Tumor Immunology, Research Institute, National Cancer Center, Goyang, Gyeonggi-do, \\ Republic of Korea \\ Correspondence to: Ho Kyung Seo, MD, PhD. Department of Urology, Center for Urologic Cancer, Hospital/Division of Tumor Immunology, \\ Research Institute, National Cancer Center, 323 Ilsan-ro, Ilsandong-gu, Goyang-si, Gyeonggi-do, 410-769, Republic of Korea. \\ Email: seohk@ncc.re.kr. \\ Provenance and Peer Review: This article was commissioned and reviewed by the Section Editor Xiao Li, MD (Department of Urology, Jiangsu Cancer \\ Hospital \& Jiangsu Institute of Cancer Research \& Nanjing Medical University Affiliated Cancer Hospital, Nanjing, China). \\ Comment on: Feld E, Harton J, Meropol NJ, et al. Effectiveness of first-line immune checkpoint blockade versus carboplatin-based chemotherapy for \\ metastatic urothelial cancer. Eur Urol 2019;76:524-32.
}

Submitted Mar 23, 2020. Accepted for publication Apr 01, 2020.

doi: $10.21037 /$ tau. 2020.04 .03

View this article at: http://dx.doi.org/10.21037/tau.2020.04.03

Cisplatin-based combination chemotherapy (CT) has been widely accepted as the initial treatment for cisplatin-eligible patients with metastatic urothelial cancer (mUC) of the bladder and upper urinary tract. Although these tumors are very sensitive to this treatment, only a small proportion of patients with these tumors may be cured, and most of the cases recur eventually within a short time. Another concern associated with this treatment is cisplatin-related toxicity. In addition, not all patients with urothelial cancer are appropriate candidates for cisplatin therapy. Up to $50 \%$ of patients with $\mathrm{mUC}$ are cisplatin-ineligible patients because of age or comorbidities such as impaired renal function, neuropathy, and heart failure (1). Other CT options for cisplatin-ineligible mUC patients include carboplatin-based combination CT or non-platinum based combination CT (2-4). However, these combinations are inferior due to lower response rates, shorter response durations, and lower OS than cisplatin-based CT (5).

The emergence of immunotherapy (IO) has revolutionized the paradigm of treatment of advanced and mUC. Checkpoint inhibitors target programmed cell death protein 1 (PD-1) or programmed cell death 1 ligand 1 (PDL1) and have shown durable response in approximately $20 \%$ of patients with platinum-refractory mUC (6-10). Based on these results, the FDA has approved five PD-1/PD-L1 inhibitors in this setting. In addition, recently, atezolizumab and pembrolizumab have been tested in single-arm trials in cisplatin-ineligible patients with $\mathrm{mUC}$ with durable response in $\sim 25 \%$ of the study participants $(11,12)$. Based on these, the FDA approved atezolizumab and pembrolizumab as the first-line treatment for cisplatin-ineligible patients with mUC and high expression of PD-L1. However, this approval is primarily based on surrogate endpoints such as objective response rates and not overall survival (OS) data. Furthermore, since there is no direct comparison between $\mathrm{CT}$ and IO in this setting, clinicians must adequately manage both therapies at their discretion. In the absence of randomized clinical trials, the most useful data for this population are the indirect comparison between first-line carboplatin-based CT and immune checkpoint blockade therapy in cisplatin-ineligible mUC patients, although the inclusion criteria in these studies were different. This comparison showed that the objective response rate of carboplatin and gemcitabine (42\%) (13) was nearly double compared to that of IO such as checkpoint inhibitors $(23-24 \%)(12,14)$. However, interestingly, the OS rate was 15.9 months and 9.3 months for the atezolizumab and CT study, respectively (15).

New retrospective real-world data by Feld et al. (16) demonstrate the effects of carboplatin-based CT and systemic IO as a primary treatment for those patients with locally advanced or mUC who are ineligible for cisplatinbased CT. In this study, using the Flatiron Health database, the data of patients receiving primary carboplatin-based CT 
$(\mathrm{n}=1,530)$ or $\mathrm{PD}-1 / \mathrm{PD}-\mathrm{L} 1$ inhibitor $(\mathrm{n}=487)$ were analyzed. Propensity score-based analysis was used to reduce the risk of selection bias inherent in the retrospective nature of the study. The main finding was that the group treated with IO had a lower OS at 12 months $(39.6 \%$ versus $46.1 \%)$ but a higher OS at 36 months (28.3\% vs. $13.3 \%)$ than did the group receiving carboplatin-based CT. This is probably due to the nature of the response observed with IO. Indeed, patients who do not respond to IO and reported hyperprogression less frequently than in reality might account for early reduced survival in the IO group. In contrast, the long-term benefits of IO include providing a durable response to a significant proportion of patients. This result is similar to the data on the durability of the reaction by conventional $\mathrm{PD}-1 / \mathrm{PD}-\mathrm{L} 1$ inhibitors (7,9$12,15,17)$.

The study by Feld et al. (16) has several limitations including the lack of available data on key prognostic variables used to determine cisplatin ineligibility of enrolled patients such as renal dysfunction, performance status, presence of visceral metastasis, hearing loss, peripheral neuropathy, and heart failure. Furthermore, these realworld data might not reflect the real-world situation because, after May 18, 2018, monotherapy using immune checkpoint inhibitors is used to treat cisplatin-ineligible mUC patients who are PD-L1 positive (approximately $30 \%$ of all tumor) or those who are ineligible for any platinumcontaining CT. Lastly, there was a difference in the rate of receiving second-line therapy between the carboplatinbased CT and systemic IO groups (47\% versus $22 \%$ ) which may affect the OS, the primary endpoint of the study. Second-line regimen using cisplatin-based CT was used in $10(9.4 \%)$ and 37 (5.7\%) patients who might be cisplatineligible. Despite the above limitations, the results of this study provide the clinicians awaiting phase III trials with important findings to advise those patients with $\mathrm{mUC}$ in the first-line setting who are ineligible for cisplatin-based CT.

The high initial response rate of carboplatin-based $\mathrm{CT}$ in cisplatin-ineligible mUC patients as the first-line treatment makes it an important treatment option for patients with high tumor burden that induces pain and local obstruction Moreover, IO drugs are the first secondline treatment available after progression of the disease following first-line CT. Further clinical trials and longterm follow-up are needed to define the role of IO drugs in the treatment of locally advanced and $\mathrm{mUC}$ in a first-line setting. Currently, four large randomized phase III trials are underway to help understand the efficacy and toxicity of IO drug monotherapy and platinum-based CT with IO drug combinations (18-21). However, in the absence of subsequent randomized trials, the study by Feld et al. (16) is quite considerable. In addition, some subgroups of patients (possibly suffering from high tumor burden) may still benefit from CT suggesting that IO drugs could be a promising option in this setting. However, according to the findings of the improved 12-month OS with carboplatinbased CT but superior 3-year OS with IO, we need a precise IO strategy including the development of predictive markers for determining the first-line CT in cisplatinineligible mUC patients.

\section{Acknowledgments}

We would like to thank Editage (www.editage.co.kr) for English language editing.

Funding: This study was supported by the Korean National Cancer Center (NCC1810866).

\section{Footnote}

Conflicts of Interest: Both authors have completed the ICMJE uniform disclosure form (available at http://dx.doi. org/10.21037/tau.2020.04.03). The authors have no conflicts of interest to declare.

Ethical Statement: The authors are accountable for all aspects of the work in ensuring that the accuracy or integrity of the work has been appropriately investigated and resolved.

Open Access Statement: This is an Open Access article distributed in accordance with the Creative Commons Attribution-NonCommercial-NoDerivs 4.0 International License (CC BY-NC-ND 4.0), which permits the noncommercial replication and distribution of the article with the strict proviso that no changes or edits are made and the original work is properly cited (including links to both the formal publication through the relevant DOI and the license). See: https://creativecommons.org/licenses/by-nc-nd/4.0/.

\section{References}

1. Galsky MD, Hahn NM, Rosenberg J, et al. Treatment of patients with metastatic urothelial cancer "unfit" for cisplatinbased chemotherapy. J Clin Oncol 2011;29:2432-8.

2. Witjes JA, Babjuk M, Bellmunt J, et al. EAU-ESMO consensus statements on the management of advanced 
and variant bladder cancer-an international collaborative multistakeholder effort: under the auspices of the EAUESMO guidelines committees. Eur Urol 2020;77:223-50.

3. Calabro F, Lorusso V, Rosati G, et al. Gemcitabine and paclitaxel every 2 weeks in patients with previously untreated urothelial carcinoma. Cancer 2009;115:2652-9.

4. Meluch AA, Greco FA, Burris HA 3rd, et al. Paclitaxel and gemcitabine chemotherapy for advanced transitional cell carcinoma of the urothelial tract: a phase II trial of the Minnie pearl cancer research network. J Clin Oncol 2001;19:3018-24.

5. Galsky MD, Chen GJ, Oh WK, et al. Comparative effectiveness of cisplatin-based and carboplatin-based chemotherapy for treatment of advanced urothelial carcinoma. Ann Oncol 2012;23:406-10.

6. Rosenberg JE, Hoffman-Censits J, Powles T, et al. Atezolizumab in patients with locally advanced and metastatic urothelial carcinoma who have progressed following treatment with platinum-based chemotherapy: a single-arm, multicentre, phase 2 trial. Lancet 2016;387:1909-20.

7. Apolo AB, Infante JR, Balmanoukian A, et al. Avelumab, an anti-programmed death-ligand 1 antibody, in patients with refractory metastatic urothelial carcinoma: results from a multicenter, phase Ib study. J Clin Oncol 2017;35:2117-24.

8. Massard C, Gordon MS, Sharma S, et al. Safety and efficacy of durvalumab (MEDI4736), an anti-programmed cell death ligand-1 immune checkpoint inhibitor, in patients with advanced urothelial bladder cancer. J Clin Oncol 2016;34:3119-25.

9. Bellmunt J, de Wit R, Vaughn DJ, et al. Pembrolizumab as second-line therapy for advanced urothelial carcinoma. N Engl J Med 2017;376:1015-26.

10. Sharma P, Retz M, Siefker-Radtke A, et al. Nivolumab in metastatic urothelial carcinoma after platinum therapy (CheckMate 275): a multicentre, single-arm, phase 2 trial. Lancet Oncol 2017;18:312-22.

11. Balar AV, Castellano D, O'Donnell PH, et al. First-line pembrolizumab in cisplatin-ineligible patients with locally advanced and unresectable or metastatic urothelial cancer (KEYNOTE-052): a multicentre, single-arm, phase 2 study. Lancet Oncol 2017;18:1483-92.

12. Balar AV, Galsky MD, Rosenberg JE, et al. Atezolizumab as first-line treatment in cisplatin-ineligible patients with locally advanced and metastatic urothelial carcinoma: a single-arm, multicentre, phase 2 trial. Lancet 2017;389:67-76.

13. De Santis M, Bellmunt J, Mead G, et al. Randomized phase II/III trial assessing gemcitabine/carboplatin and methotrexate/carboplatin/vinblastine in patients with advanced urothelial cancer "unfit" for cisplatin-based chemotherapy: phase II results of EORTC study 30986. J Clin Oncol 2009;27:5634-9.

14. Necchi A, Anichini A, Raggi D, et al. Pembrolizumab as neoadjuvant therapy before radical cystectomy in patients with muscle-invasive urothelial bladder carcinoma (PURE01): an open-label, single-arm, phase II study. J Clin Oncol 2018;36:3353-60.

15. Powles T, Duran I, van der Heijden MS, et al. Atezolizumab versus chemotherapy in patients with platinum-treated locally advanced or metastatic urothelial carcinoma (IMvigor211): a multicentre, open-label, phase 3 randomised controlled trial. Lancet 2018;391:748-57.

16. Feld E, Harton J, Meropol NJ, et al. Effectiveness of firstline immune checkpoint blockade versus carboplatin-based chemotherapy for metastatic urothelial cancer. Eur Urol 2019;76:524-32.

17. Powles T, O'Donnell PH, Massard C, et al. Efficacy and safety of durvalumab in locally advanced or metastatic urothelial carcinoma: updated results from a phase 1/2 open-label study. JAMA Oncol 2017;3:e172411.

18. Powles T, Galsky MD, Castellano D, et al. A phase 3 study of the first-line durvalumab (MEDI4736) \pm tremelimumab versus standard of care (SoC) chemotherapy (CT) in patients (pts) with unresectable Stage IV urothelial bladder cancer (UBC): DANUBE. J Clin Oncol 2017;34. DOI: 10.1200/JCO.2016.34.15_suppl.TPS4574.

19. Powles T, Loriot Y, Gschwend JE, et al. KEYNOTE-361: Phase 3 trial of pembrolizumab \pm chemotherapy versus chemotherapy alone in advanced urothelial cancer. Eur Urol Suppl 2018;17:e1147-8.

20. Galsky MD, Powles T, Li S, et al. A phase 3, open-label, randomized study of nivolumab plus ipilimumab or standard of care (SOC) versus SOC alone in patients (pts) with previously untreated unresectable or metastatic urothelial carcinoma (mUC; CheckMate 901). J Clin Oncol 2018;36. DOI: 10.1200/JCO.2018.36.6_suppl.TPS539.

21. Galsky MD, Grande E, Davis ID, et al. IMvigor130: A randomized, phase III study evaluating first-line (1L) atezolizumab (atezo) as monotherapy and in combination with platinum-based chemotherapy (chemo) in patients (pts) with locally advanced or metastatic urothelial carcinoma (mUC). J Clin Oncol 2018. doi: 10.1200/ JCO.2018.36.15_suppl.TPS4589.

Cite this article as: Kwon WA, Seo HK. Optimizing frontline therapy in advanced urothelial cancer. Transl Androl Urol 2020;9(3):983-985. doi:10.21037/tau.2020.04.03 